\title{
Potential for clinical pancreatic islet xenotransplantation
}

\author{
This article was published in the following Dove Press journal: \\ Transplant Research and Risk Management \\ 24 September 2014 \\ Number of times this article has been viewed
}

\author{
Rita Bottino' \\ Santosh Nagaraju ${ }^{2}$ \\ Vikas Satyananda ${ }^{2}$ \\ Hidetaka Hara ${ }^{2}$ \\ Martin Wijkstrom² \\ Massimo Trucco' \\ David KC Cooper ${ }^{2}$ \\ 'Institute of Cellular Therapeutics, \\ Allegheny Health Network, ${ }^{2}$ Thomas \\ E Starzl Transplantation Institute, \\ Department of Surgery, University \\ of Pittsburgh, Pittsburgh, PA, USA
}

Correspondence: Rita Bottino Institute of Cellular Therapeutics, Allegheny-Singer Research Institute, Allegheny Health Network, 320 East North Avenue, Pittsburgh, PA I52 I 2-4772, USA

Tel + I 4I23596395

Fax + I 4123596987

Email rbottino@wpahs.org
Abstract: Diabetes mellitus is increasing worldwide. Type 1 diabetes can be treated successfully by islet allotransplantation, the results of which are steadily improving. However, the number of islets that can be obtained from deceased human donors will never be sufficient to cure more than a very small percentage of patients who might benefit from transplantation. Although there are some differences in glucose metabolism between pigs and humans, the use of pigs could provide an unlimited supply of islets, and the insulin produced would undoubtedly control glucose levels. Transplantation of islets into the portal vein results in islets residing in the liver; however, an early inflammatory response and rejection remain problematic, even when the recipient is receiving immunosuppressive therapy. In the long term, immunosuppressive drugs may exhibit toxicities to patients and specifically harm the islet cells. In contrast, encapsulation techniques provide islets with a physical barrier that prevents antibodies binding to the islet graft while still allowing insulin to be released into the recipient's circulation; in theory, patients receiving encapsulated grafts might not require exogenous immunosuppressive therapy. Nonhuman primates with encapsulated pig islet transplants have remained insulin-independent for several weeks, but long-term efficacy remains uncertain. Furthermore, techniques are now available to knock out genes from the pig and/or insert human genes, thus rendering the antigenic structure of pigs closer to that of humans, and providing protection from the human immune response. Islet transplantation from genetically engineered pigs has been followed by insulin independence in a small number of nonhuman primates for greater than 1 year. Neonatal islets have some advantages over adult islets in that they are easier to isolate and culture, and have the ability to proliferate during the first few months after transplantation. In 2009, the International Xenotransplantation Association set up a group to encourage and advise on clinical trials of pig islet xenotransplantation; this group's guidelines are discussed. Clinical trials of encapsulated pig islets are already under way.

Keywords: diabetes, islets, pancreatic, pig, xenotransplantation

\section{The problem of type I diabetes}

Diabetes is increasing in frequency worldwide, not only in the Western world, but in many of the most populous countries of Asia, as Western culture, including diet, encroaches upon traditional ways of life (Table 1). Furthermore, diabetes is already epidemic, with an increasing health burden that in some countries absorbs $>10 \%$ of their annual expenditure for health care. ${ }^{1}$

Diabetes has traditionally been subdivided into type 1 (T1D; autoimmune) and type 2 (T2D; with insulin resistance and metabolic syndrome); however, this subdivision is an oversimplification, with the current notion that several different mechanisms can lead to the onset of diabetes. ${ }^{2}$ It is relevant to note that as recently as three decades ago, 
Table I Reported incidence of diabetes in selected countries worldwide

\begin{tabular}{lll}
\hline Region & $\begin{array}{l}\text { Estimated overall } \\
\text { prevalence of } \\
\text { TID + T2D in } \\
\text { millions (\% of adult } \\
\text { population) }\end{array}$ & $\begin{array}{l}\text { Estimated } \\
\text { new cases of } \\
\text { TID in 20 I I } \\
\text { (per I 00,000 } \\
\text { population) }\end{array}$ \\
\hline $\begin{array}{l}\text { Europe } \\
\begin{array}{l}\text { Southeast Asia } \\
\text { (includes India) }\end{array}\end{array}$ & $\begin{array}{l}52.6(8.1 \%) \\
\text { North America }\end{array}$ & $17,800(1.9)$ \\
$\begin{array}{l}\text { and Caribbean } \\
\text { South and }\end{array}$ & $37.7(7.3 \%)$ & $1800(1.2)$ \\
$\begin{array}{l}\text { Central America } \\
\text { Middle East and }\end{array}$ & $25.1(8.7 \%)$ & $14,600(3.0)$ \\
$\begin{array}{l}\text { North Africa } \\
\text { Africa }\end{array}$ & $32.8(9.1 \%)$ & $5,500(1.1)$ \\
$\begin{array}{l}\text { Western Pacific (includes } \\
\text { People's Republic of China) }\end{array}$ & $131.9(8.5 \%)$ & $10,800(1.7)$ \\
\hline
\end{tabular}

Note: Data from. ${ }^{54,55}$

Abbreviations: TID, type I diabetes; T2D, type 2 diabetes.

all diabetic children and adolescents were assumed to have T1D, whereas more recently the incidence of $\mathrm{T} 2 \mathrm{D}$ among pubertal and postpubertal adolescents has risen dramatically. ${ }^{3}$ Despite the different etiology, the consequences of both types of diabetes are similar and account for increased risk for cardiovascular disease, neuropathy, blindness, and kidney failure. According to the current statistics, diabetes is the fourth-leading cause of death worldwide. ${ }^{4}$ New glucose-lowering treatments, especially glucagon-like peptide 1-receptor agonists and sodium glucose cotransporter-2 inhibitors, offer advantages over traditional antidiabetic drugs used to regulate $\mathrm{T} 2 \mathrm{D}$ by promoting weight loss while improving glucose control. ${ }^{5}$ However, exogenous insulin injections are the only effective treatment for T1D unless a transplant (pancreas or pancreatic islets) is carried out.

Pancreas transplantation is an effective approach to treat T1D. According to the American Diabetes Association, it should be considered an acceptable therapeutic alternative to continued insulin therapy in diabetic patients with imminent or established end-stage renal disease, who have had or plan to have a kidney transplant. In the absence of indications for kidney transplantation, pancreas transplantation alone should be considered in patients who have severe metabolic complications and failure of insulin-based management. ${ }^{6}$ At present, only adult patients meet the requirements for pancreas transplantation, due to the invasiveness of the surgery required and the relatively high incidence of complications associated with the procedure. It is not recommended for pediatric and adolescent patients, those individuals who would most benefit from effective $\beta$-cell replacement.
In contrast, transplantation of pancreatic islets holds significant potential advantages over whole-pancreas transplantation. In this procedure, islets are extracted from the pancreas of deceased donors by means of a process based on digestion with exogenous enzymes (collagenases and neutral proteases). Islets are then rescued from the exocrine tissue via a process of density-gradient separation. Although mechanical and chemical stresses necessary to the isolation process may potentially damage some of the islets, this risk can be minimized by the careful application of the techniques involved. Islet cells can survive up to several days in culture, maintaining their ability to secrete insulin in vitro, and following transplantation, in vivo. Isolated islets are typically transplanted via intraportal injection. Islet infusion is usually carried out by a minimally invasive procedure, such as percutaneous transhepatic portal catheterization guided by ultrasound.

The risks associated with islet transplantation are substantially lower than those of whole-pancreas transplantation, making it more suitable, especially for adolescents, who would potentially receive the benefits over many years. More than one infusion - corresponding to an islet mass obtained from at least two cadaveric pancreas donors - is typically required to achieve insulin independence. The need for a greater number of donor organs for islet transplantation, in comparison to whole-pancreas transplantation, is in part counterbalanced by the fact that islets can be isolated from marginal donors not suitable for whole-pancreas transplantation (eg, because of vascular abnormalities or fatty organs).

Both pancreas and islet transplantation require lifelong immunosuppressive therapy to prevent rejection. Islet transplantation has been shown to be an effective treatment for T1D. Increased experience with the procedure, and the techniques involved with it, have produced steadily improving results. Insulin independence can now be maintained for at least 3 years in $>50 \%$ of patients. The single major limiting factor of this technique, however, is the finite number of acceptable human cadaveric pancreases available. The number of islets that can be obtained from deceased human donors will never be sufficient to treat more than a very small percentage of patients with T1D, especially considering the need for more than one pancreas to produce sufficient islets for one recipient. Another source of acceptable islets is greatly needed.

\section{Pigs as a source of islet cells for transplantation}

Tissues from pigs have been routinely and safely used for medical purposes for decades. Although there are 
some differences in glucose metabolism between pigs and humans, ${ }^{7}$ pigs could provide an unlimited supply of islets for transplantation into patients with T1D, and the insulin produced would likely control blood glucose levels. Pig insulin (which differs from human insulin by only one amino acid) was used in the treatment of patients with T1D for many decades until recombinant human insulin was synthesized. ${ }^{8}$

T1D occurs when the autologous immune cells target antigens expressed in the insulin-producing cells of the pancreas. As a result of this selective destruction of islet $\beta$-cells by autoreactive T lymphocytes, the ability to produce insulin sufficient to maintain normal levels of glucose in the body is lost, resulting in hyperglycemia. Recurrence of autoimmunity has been reported in both recipients of allogeneic pancreas and islet transplantation, where it contributes to $\beta$-cell graft destruction. ${ }^{9,10}$ The immunosuppressive therapy administered to organ and cell-transplant recipients to prevent rejection establishes hyporesponsiveness toward the graft, but it also modulates autoreactive $\mathrm{T}$ cells as well, making recurrent autoimmunity in transplant recipients somewhat less destructive, although not completely eliminated. However, drugs that suppress the immune system are associated with increased risk of infections and malignancies, and some immunosuppressive agents are known to have islet $\beta$-cell toxicity.

The question whether xenogeneic islet transplantation might avoid recurrent autoimmunity in patients with T1D is being studied, but has yet to produce a definitive answer. Promising lines of inquiry carried out in models of pig islet transplantation into nonobese diabetic mice ("NOD" mice that spontaneously develop autoimmune diabetes similar to T1D in humans) show that adult pig islets are partially resistant to recurrent autoimmunity ${ }^{11}$ and pig fetal islets are likely even more resistant. ${ }^{12}$ The results of islet transplantation in the pig-to-mouse model, if confirmed, offer several very relevant advantages of xenoislet transplantation over allogeneic islet transplantation.

Another potentially important feature of porcine islet $\beta$-cells is that unlike human $\beta$-cells, they do not overproduce amyloids. Islet amyloid polypeptide (amylin) is secreted from pancreatic islet $\beta$-cells and converted to amyloid deposits. Amylin-fibril formation in the pancreas may cause islet-cell dysfunction and death. ${ }^{13}$ Porcine amylin differs from the human sequence at ten positions, and includes substitutions predicted to reduce its amyloidogenicity. ${ }^{14}$ Lack of amyloid deposits in the islet $\beta$-cells after pig islet transplantation in diabetic monkeys has also been confirmed. ${ }^{15}$
The first documented clinical trial of pig-to-human islet xenotransplantation (more exactly fetal islet-like cell clusters) took place as early as $1994 .{ }^{16}$ Porcine pancreatic cells were injected intraportally or placed under the capsule of a kidney allograft. Some patients excreted small amounts of porcine $\mathrm{C}$ peptide in the urine for more than 6 months, and biopsy specimens showed morphologically intact epithelial cells stained positively for both insulin and glucagon. None of the patients, however, demonstrated an improvement in metabolic control. ${ }^{16}$

Experimental transplantation has contributed in the last two decades to shed light on the critical mechanisms occurring after islet xenotransplantation. We now know that when pig islets are transplanted into the portal vein of diabetic nonhuman primates (NHPs), there is an immediate and significant loss of islets from a complex interplay between several mechanisms known as the instant blood-mediated inflammatory reaction (IBMIR), ${ }^{17}$ and rejection of the islets takes place fairly rapidly. ${ }^{18}$ Both of these phenomena (IBMIR and rejection) are related to differences in the expression of antigens between the pig and NHPs, and would necessarily be the same between the pig and humans.

In vitro exposure of pig islets to human blood triggers coagulation, islet-membrane leakage, antibody deposition, soluble complement activation, including the membrane attack complex, and mitochondrial dysfunction. ${ }^{19,20}$ To some extent, some of these events occur also in autologous and allogeneic islet/blood combinations, but islet damage is worse in the xenogeneic setting.

\section{Genetically engineered pigs}

The ability to develop genetically engineered pigs has brought the prospect of successful pig islet xenotransplantation much closer to reality. Techniques are now available to knock out genes from the pig and/or insert human genes, thus rendering the pig closer in its antigenic structure to humans and providing protection from the human immune response. Humans and Old World monkeys have natural preformed antibodies (present in serum in the absence of an apparent specific antigen contact) against pig antigens, ${ }^{21,22}$ particularly against galactose- $\alpha 1,3$-galactose (Gal) that is expressed on many pig cells, including islets. ${ }^{23}$ When pig tissue is transplanted into humans or Old World monkeys, preformed natural antibodies bind to pig antigens and initiate complement activation, resulting in destruction of the graft vasculature with subsequent interstitial hemorrhage edema and graft failure. The pathophysiological mechanism is very similar to that seen when an allograft is transplanted across the ABO 
blood-group barrier. ${ }^{24}$ For pig islet xenotransplantation to become fully successful, steps had to be taken to overcome this immune response in humans. After identifying the gene for $\alpha 1,3$-galactosyltransferase, which is the enzyme that synthesizes Gal, ${ }^{25,26}$ it was possible to knock out the gene by homologous recombination ${ }^{27}$ using somatic cell nuclear transfer technology. The resulting $\alpha 1,3$-galactosyltransferase geneknockout (GTKO) pigs were first available for experimental studies in $2003 .{ }^{28}$ The transplantation of organs from GTKO pigs into NHPs resulted in a reduced incidence of hyperacute rejection. ${ }^{29,30}$ However, this was to a lesser extent than expected, suggesting that additional xenoantigens may exert a role in immunological incompatibility between species.

In addition, genes for human complement-regulatory proteins (eg, CD46,CD55) have been inserted into pig cells ${ }^{31}$ in order to protect them from human complement-mediated injury. Furthermore, pigs that express one or more human thromboregulatory gene (eg, thrombomodulin, TFPI) and/or anti-inflammatory gene (eg, CD39) are being developed, with the aim of reducing thrombotic microangiopathy in the graft and/or systemic consumptive coagulopathy in the recipient (Wijkstrom et al, unpublished data, 2014). ${ }^{32-34}$

These measures have greatly reduced the innate immune response of human antibodies towards pig antigens, and the adaptive T-cell-dependent response can be largely controlled by the newer immunosuppressive agents that have become available. There is every prospect, therefore, that pig islets can be protected sufficiently to enable them to render the patient insulin-independent for a prolonged period of time (years, rather than weeks or months).

\section{Pig islet transplantation in nonhuman primates}

A number of groups have explored pig islet transplantation in NHPs rendered diabetic by streptozotocin. Within the last several years, the transplantation of neonatal or adult pig islets, or even embryonic pancreatic tissue, has been reported to restore normoglycemia for a period $>6$ months in the absence of exogenous insulin administration. Glycemic control was successfully achieved, however, at the cost of higher islet masses infused than those required in human allogeneic transplantation settings. ${ }^{35-37}$ Furthermore, one group has achieved this success using encapsulated adult pig islets in the absence of exogenous immunosuppressive therapy. ${ }^{38}$

Encapsulation techniques are aimed at providing a physical barrier that prevents antibody binding to the graft but enables insulin to be released from the graft into the recipient circulation. ${ }^{39}$
In theory, immunosuppressive therapy should not be required to maintain graft function and survival. However, at the present time, these techniques have only extended islet function for approximately 6 months. It is not yet certain whether loss of islet function is related to immune destruction of the graft or to lack of sufficient nutrients reaching the islets to maintain viability, because of pericapsular fibrosis.

In contrast, after the transplantation of free (nonencapsulated) islets, eg, into the portal vein where they reside in the liver, IBMIR and rejection remain problematic even when the recipient is receiving immunosuppressive therapy. Efforts are being made to further genetic engineering pigs so that their islets are protected from IBMIR and rejection, ${ }^{39}$ and some progress is being made. For example, our own group has reported the survival of pig islets and control of diabetes in immunosuppressed diabetic NHPs for $>1$ year without the need for any insulin therapy (Figure 1). ${ }^{37,40}$

Neonatal islets have some advantages over adult islets, in that they are easier to isolate and culture and have the ability to proliferate during the first few months after transplantation. ${ }^{41,42}$ However, they express higher levels of Gal than adult pig islets, and therefore GTKO pigs are likely to prove essential in overcoming this hurdle. Islets from adult pigs are particularly difficult to isolate satisfactorily, as the islets have more fragile capsules than human islets and are more susceptible to damage by the isolation process. They are consequently more easily destroyed by the IBMIR than human islets. ${ }^{19}$ Neonatal islets may therefore prove preferable as a source for clinical transplantation.

Furthermore, as a practical consideration, the pigs used as sources of islets may be required to be housed in a strict biosecure environment to prevent microorganisms from infecting the pig and possibly being transferred with the islets to the human recipient. It will be more efficient logistically, and more cost-effective, if the pancreases can be obtained from pigs during the first postnatal month, instead of after housing for a year or more until they have reached adult status.

\section{Metabolic aspects of islet xenotransplantation}

Besides immunological incompatibilities between humans and animals, metabolic aspects deserve consideration. Glucose homeostasis is the result of a complex biochemical regulation involving different internal systems. Insulin and glucagon are key hormones to maintain physiologic equilibrium, but multiple species-specific factors contribute to maintain a metabolic balance. Differences in metabolic parameters between cynomolgus monkeys, pigs, and humans have been 

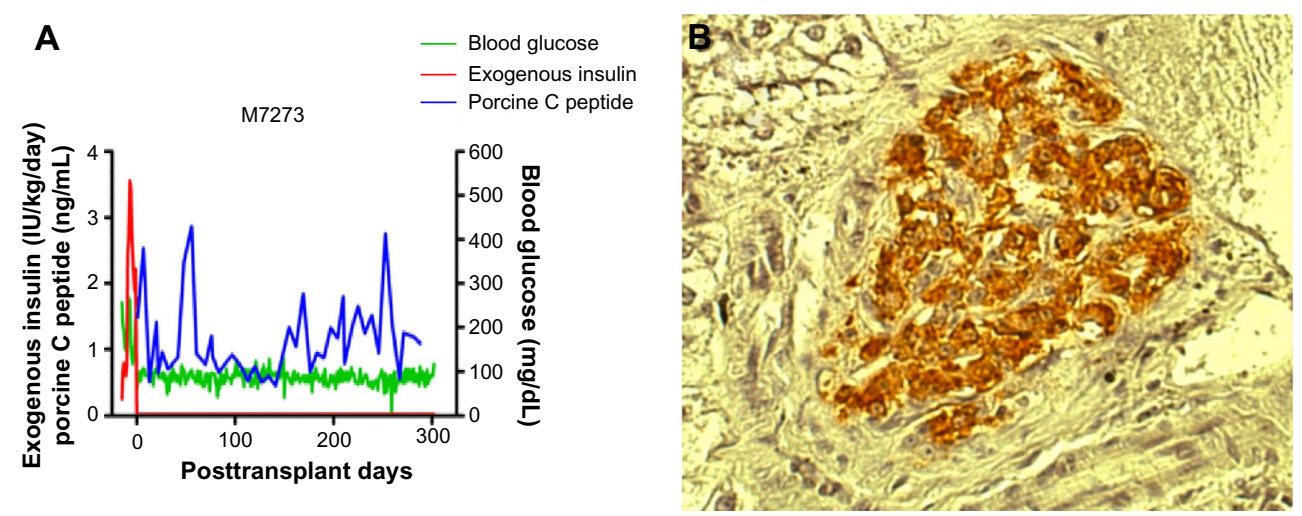

Figure I (A) Blood glucose, porcine C peptide measurements, and insulin requirements in a cynomolgus monkey that remained insulin-independent and normoglycemic for more than I year after adult porcine islet xenotransplantation (using a pig transgenic for the human complement-regulatory protein CD46) at the University of Pittsburgh. (B) Histopathology with insulin immunostaining of the liver 12 months after porcine islet xenotransplantation into the portal vein in the same cynomolgus monkey as in (A). Islet morphology is well preserved. No islets were detectable in the monkey's native pancreas.

observed. ${ }^{7,43}$ Monkeys are characterized by high circulating $\mathrm{C}$ peptide and insulin levels, and by low glucose levels. In contrast, pigs exhibit low $\mathrm{C}$ peptide and insulin levels and higher blood glucose levels. Although both species respond to glucose and food stimulation, differences in insulin output and glucose homeostasis have been noted.

The molecular differences in porcine and monkey $\mathrm{C}$ peptide and insulin are not substantial, but these differences may interfere in their kinetics and in vivo activity. Human and porcine insulins, however, have demonstrated equivalent therapeutic activity. ${ }^{7}$ Human insulin requirements are between those of pigs and monkeys. This may be of importance in respect to the eventual translation of pig islet transplantation into clinical practice, since human insulin demands are lower than those of monkeys. ${ }^{7}$

Considering the performance of pig islets in NHPs, whose metabolic demand is higher than that of a pig, and more importantly higher than that of a human, we might argue that a good metabolic outcome could be reached in humans with pig islets. Although the definition of metabolic target in human recipients of pig islet transplantation has not been codified yet, reduction in glycated hemoglobin $\left(\mathrm{HbA}_{1 \mathrm{c}}\right)$ and/or exogenous insulin requirements, if not insulin independence, are reasonable goals. As studies progress, a consensus will be reached.

\section{Clinical trials of pig islet xenotransplantation}

Because the results of islet xenotransplantation in NHPs are improving steadily and pigs with multiple genetic modifications are becoming more readily available, increased thought is being given to initiate clinical trials. Indeed, clinical trials of encapsulated pig islets have already been undertaken, although, with one exception, these have not been well regulated, and the results have not been reported fully. The exception is a trial currently being undertaken in New Zealand with oversight by that country's Ministry of Health. ${ }^{44}$ Although the results of islet-graft performance have not been disclosed yet, preliminary data indicate that no transmission of either porcine endogenous retroviruses (PERVs) or other porcine microorganisms was detected, as also reported by Heneine et al following the first trial of clinical fetal islet-like cluster transplantation in immunosuppressed patients. ${ }^{45,46}$ It would appear from these various trials that there have been no untoward complications, even though no or few clear benefits to the patients have been reported.

For clinical trials of free (ie, nonencapsulated) islet transplantation to be carried out, however, there is greater risk of such complications as infections, because of the need for immunosuppressive therapy. This is particularly important in patients with T1D, who are often young and may therefore require immunosuppressive therapy for many years. Nevertheless, in those patients undergoing islet allotransplantation, the number of serious complications has to date been relatively few. ${ }^{47}$

\section{The International Xenotransplantation Association guidelines}

In 2009, the International Xenotransplantation Association (IXA) set up a group to advise on clinical trials of pig islet xenotransplantation. ${ }^{48}$ This committee investigated 1) the ethical requirements and regulatory framework that would be required, 2) the nature and housing of source pigs, 3) the preparation of the pig islet product and its testing, 4) preclinical efficacy and complication data that might be required to 
justify a clinical trial, 5) strategies to prevent transmission of PERVs, 6) patient selection, and 7) the matter of informed consent. The committee indicated that in the light of increasing experience, the guidelines it had put forward might well require modification. There are certainly some areas where modification might be beneficial.

\section{What, if any, experimental work needs to have been carried out before initiating a clinical trial?}

The IXA committee recommended that no clinical trial should be undertaken unless there had been preclinical studies in NHPs. While it is true that these experiments are expensive and time-consuming, and may not always accurately reflect the outcome of islet xenotransplantation in humans, they can be an important step in assuring the safety of the patient. In that regard, by ensuring the safety of human patients, even if the NHP study fails, the cost cannot be considered too high. A case can be made that if there are good data from pig-to-rodent models to indicate that a clinical trial would provide a realistic possibility of benefit to the patient and would be safe, studies in NHPs may not be essential. Where encapsulated islets are concerned, the lack of the need for immunosuppressive therapy requires less stringent regulation, and evidence of efficacy from rodent models may possibly suffice under certain circumstances. However, when free islets are being transplanted, then some evidence of efficacy in a pig-to-NHP model will probably be expected by the national regulatory authorities.

\section{What, if any, preliminary clinical studies need to have been carried out before initiating a clinical trial?}

If the group planning a clinical trial has experience in the management of immunosuppressed patients with organ or islet allotransplants, then the need for studies in NHPs is perhaps reduced further. Centers with experience with islet isolation, particularly if it is of both human and pig islets, are also in a stronger position to initiate a clinical trial. Experience in isolating islets (human or pig) under the conditions required in a Good Manufacturing Practice facility would be considered essential.

\section{What microbiological "safety" tests are required of the pigs and islets?}

In the US, the approach from the Food and Drug Administration has been that the source pigs should be housed in a biosecure facility and should be tested at intervals to ensure that any "product", eg, islets, from the pig that is transplanted into human subjects is free of significant infectious microorganisms. ${ }^{49}$ An argument could be made that if the islets themselves are proven to be sterile, then this may be sufficient to enable clinical islet transplantation to be undertaken. Most microorganisms could be excluded by testing the islets during the period of ex vivo culture before transplantation, but it may be difficult to demonstrate that the islets are free of significant viruses at this stage. Therefore, some testing of the herd to ensure that it is free of important viruses will probably be necessary.

The presence of PERVs in every pig cell nucleus has been of concern in the past, ${ }^{50}$ as the PERVs will undoubtedly be transferred to the patient with the islets. However, the data accumulated to date from humans and NHPs that have been exposed to pig tissues indicates that transmission is extremely rare, and not associated with significant complication. Furthermore, methods are available today to minimize the risk of PERV activation. ${ }^{51}$

\section{Which patients should be selected for the initial clinical trial?}

At present, most patients selected for islet allotransplantation are those experiencing significant life-threatening hypoglycemic episodes, and these would also be potential patients for pig islet xenotransplantation. The possibility of infections from unknown pathogens associated with the immunosuppression required for pig islet xenotransplantation needs to be weighed against the risk of developing major complications from diabetes at an early age.

\section{On what basis would the trial be considered successful?}

We would suggest that control of diabetes, or at least greatly reduced need for insulin therapy and a reduction in $\mathrm{HbA}_{1 \mathrm{c}}$, possibly with additional benefits (eg, a reduction in the number of hypoglycemic episodes) for $>1$ year, should be considered a successful trial. A reduction in $\mathrm{HbA}_{1 \mathrm{c}}$ levels, even while maintaining the same insulin requirements, would be beneficial to prevent the long-term complications of diabetes. It should be borne in mind that in the 1960s and 1970 s the function of kidney allotransplants was often only for some weeks or months, whereas today, with much greater experience and improved immunosuppressive agents, graft function frequently extends for very many years. Similarly, the results of islet allotransplantation, which were initially disappointing, have improved significantly during the past 
14 years since the first encouraging report was published in 2000. ${ }^{52,53}$ Therefore, in the initial clinical trial of islet xenotransplantation, the expectation bar should not be set too high.

\section{Regulation of the clinical trial}

Oversight and regulation of clinical trials is clearly important, and any clinical trial of pig islet transplantation should be overseen by a local committee of experts who have the power and authority to discontinue the trial if necessary. Ideally, there should also be a national or international committee of experts to provide additional regulatory authority and organization.

Having emphasized that point, we would suggest that advancing the field of pig islet xenotransplantation, which has the potential of curing hundreds of thousands of patients with T1D, should be given very high priority, and regulations should not be so restrictive that they prohibit progress. ${ }^{55}$

\section{Acknowledgments}

The authors would like to thank Michael Knoll for assisting with the preparation of the manuscript. Work on xenotransplantation at the University of Pittsburgh has been in part supported by Department of Defense grant W81XWH-06-10317 (MT), JDRF grant 6-2005-1180 (MT), NIH grants U19 AI090959-01, U01 AI068642, and R21 A1074844 (DKCC), NIH RO3 grant AI096296 (HH), and by Sponsored Research Agreements between Revivicor, Inc, Blacksburg, VA and the University of Pittsburgh.

\section{Disclosure}

The authors report no conflicts of interest in this work.

\section{References}

1. American Diabetes Association. Economic costs of diabetes in the US in 2012. Diabetes Care. 2013;36(4):1033-1046.

2. Tuomi T, Santoro N, Caprio S, Cai M, Weng J, Groop L. The many faces of diabetes: a disease with increasing heterogeneity. Lancet. 2014;383(9922):1084-1094.

3. Dabelea D, Mayer-Davis EJ, Saydah S, et al. Prevalence of type 1 and type 2 diabetes among children and adolescents from 2001 to 2009. JAMA. 2014;311(17):1778-1786.

4. Golubnitschaja O. Advanced diabetes care: three levels of prediction, prevention and personalized treatment. Curr Diabetes Rev. 2010;6(1): 42-51.

5. Scheen AJ, Van Gaal LF. Combating the dual burden: therapeutic targeting of common pathways in obesity and type 2 diabetes. Lancet Diabetes Endocrinol. Epub February 19, 2014.

6. Robertson RP, Davis C, Larsen J, Stratta R, Sutherland DE. Pancreas and islet transplantation in type 1 diabetes. Diabetes Care. 2006;29(4): 935.

7. Casu A, Bottino R, Balamurugan AN, et al. Metabolic aspects of pigto-monkey (Macaca fascicularis) islet transplantation: implications for translation into clinical practice. Diabetologia. 2008;51(1):120-129.
8. Keen H, Glynne A, Pickup JC, et al. Human insulin produced by recombinant DNA technology: safety and hypoglycaemic potency in healthy men. Lancet. 1980;2(8191):398-401.

9. Sutherland DE, Goetz FC, Sibley RK. Recurrence of disease in pancreas transplants. Diabetes. 1989;38 Suppl 1:85-87.

10. Stegall MD, Lafferty KJ, Kam I, Gill RG. Evidence of recurrent autoimmunity in human allogeneic islet transplantation. Transplantation. 1996;61(8):1272-1274.

11. Koulmanda M, Qipo A, Smith RN, Auchincloss H Jr. Pig islet xenografts are resistant to autoimmune destruction by non-obese diabetic recipients after anti-CD4 treatment. Xenotransplantation. 2003;10(2): 178-184.

12. Bai L, Tuch BE, Hering B, Simpson AM. Fetal pig beta cells are resistant to the toxic effects of human cytokines. Transplantation. 2002;73(5):714-722.

13. Lorenzo A, Razzaboni B, Weir G, Yankner BS. Pancreatic islet cell toxicity of amylin associated with type-2 diabetes mellitus. Nature. 1994;368(6473):756-760.

14. Potter KJ, Abedini A, Marek P, et al. Islet amyloid deposition limits the viability of human islet grafts but not porcine islet grafts. Proc Natl Acad Sci US A. 2010;107(9):4305-4310.

15. van der Windt DJ, Bottino R, Kumar G, et al. Clinical islet xenotransplantation: how close are we? Diabetes. 2012;61(12): 3046-3055.

16. Groth CG, Korsgren O, Tibell A, et al. Transplantation of porcine fetal pancreas to diabetic patients. Lancet. 1994;344(8934):1402-1404.

17. van der Windt DJ, Bottino R, Casu A, Campanile N, Cooper DK. Rapid loss of intraportally transplanted islets: an overview of pathophysiology and preventive strategies. Xenotransplantation. 2007;14(4):288-297.

18. Kirchhof N, Shibata S, Wijkstrom M, et al. Reversal of diabetes in non-immunosuppressed rhesus macaques by intraportal porcine islet xenografts precedes acute cellular rejection. Xenotransplantation. 2004;11(5):396-407.

19. van der Windt DJ, Marigliano M, He J, et al. Early islet damage after direct exposure of pig islets to blood: has humoral immunity been underestimated? Cell Transplant. 2012;21(8):1791-1802.

20. Bennet W, Sundberg B, Lundgren T, et al. Damage to porcine islets of Langerhans after exposure to human blood in vitro, or after intraportal transplantation to cynomologus monkeys: protective effects of sCR1 and heparin. Transplantation. 2000;69(5):711-719.

21. Oriol R, Ye Y, Koren E, Cooper DK. Carbohydrate antigens of pig tissues reacting with human natural antibodies as potential targets for hyperacute vascular rejection in pig-to-man organ xenotransplantation. Transplantation. 1993;56(6):1433-1442.

22. Good AH, Cooper DK, Malcolm AJ, et al. Identification of carbohydrate structures that bind human antiporcine antibodies: implications for discordant xenografting in man. Transplant Proc. 1992;24(2):559-562.

23. Dor FJ, Cheng J, Alt A, Cooper DK, Schuurman HJ. Gal $\alpha 1,3 \mathrm{Gal}$ expression on porcine pancreatic islets, testis, spleen, and thymus. Xenotransplantation. 2004;11(1):101-106.

24. Ekser B, Ezzelarab M, Hara H, et al. Clinical xenotransplantation: the next medical revolution? Lancet. 2012;379(9816):672-683.

25. Koike C, Friday RP, Nakashima I, et al. Isolation of the regulatory regions and genomic organization of the porcine $\alpha 1,3$-galactosyltransferase gene. Transplantation. 2000;70(9):1275-1283.

26. Koike C, Fung JJ, Geller DA, et al. Molecular basis of evolutionary loss of the $\alpha 1,3$-galactosyltransferase gene in higher primates. $J$ Biol Chem. 2002;277(12):10114-10120.

27. Dai Y, Vaught TD, Boone J, et al. Targeted disruption of the $\alpha 1,3$-galactosyltransferase gene in cloned pigs. Nat Biotechnol. 2002;20(3):251-255.

28. Phelps CJ, Koike C, Vaught TD, et al. Production of $\alpha 1,3$ galactosyltransferase-deficient pigs. Science. 2003;299(5605): 411-414.

29. Kuwaki K, Tseng YL, Dor FJ, et al. Heart transplantation in baboons using $\alpha 1$,3-galactosyltransferase gene-knockout pigs as donors: initial experience. Nat Med. 2005;11(1):29-31. 
30. Yamada K, Yazawa K, Shimizu A, et al. Marked prolongation of porcine renal xenograft survival in baboons through the use of $\alpha 1,3$ galactosyltransferase gene-knockout donors and the cotransplantation of vascularized thymic tissue. Nat Med. 2005;11(1):32-34.

31. Cozzi E, White DJ. The generation of transgenic pigs as potential organ donors for humans. Nat Med. 1995;1(9):964-969.

32. Roussel JC, Moran CJ, Salvaris EJ, Nandurkar HH, d'Apice AJ, Cowan PJ. Pig thrombomodulin binds human thrombin but is a poor cofactor for activation of human protein C and TAFI. Am J Transplant. 2008;8(6):1101-1112.

33. Lee KF, Salvaris EJ, Roussel JC, Robson SC, d'Apice AJ, Cowan PJ. Recombinant pig TFPI efficiently regulates human tissue factor pathways. Xenotransplantation. 2008;15(3):191-197.

34. Crikis S, Lu B, Murray-Segal LM, et al. Transgenic overexpression of CD39 protects against renal ischemia-reperfusion and transplant vascular injury. Am J Transplant. 2010;10(12):2586-2595.

35. Hering BJ, Wijkstrom M, Graham ML, et al. Prolonged diabetes reversal after intraportal xenotransplantation of wild-type porcine islets in immunosuppressed nonhuman primates. Nat Med. 2006;12(3):301-303.

36. Cardona K, Korbutt GS, Milas Z, et al. Long-term survival of neonatal porcine islets in nonhuman primates by targeting costimulation pathways. Nat Med. 2006;12(3):304-306.

37. van der Windt DJ, Bottino R, Casu A, et al. Long-term controlled normoglycemia in diabetic non-human primates after transplantation with hCD46 transgenic porcine islets. Am J Transplant. 2009;9(12): 2716-2726.

38. Dufrane D, Goebbels RM, Gianello P. Alginate macroencapsulation of pig islets allows correction of streptozotocin-induced diabetes in primates up to 6 months without immunosuppression. Transplantation. 2010;90(10):1054-1062.

39. Ayares D, Vaught T, Ball S, et al. Islet-specific expression of TFPI, CD39, and CTLA4Ig in transgenic pigs designed for xenoislet transplantation. Xenotransplantation. 2011;18(5):269.

40. Bottino R, Wijkstrom M, van der Windt DJ, et al. Pig to monkey xenotransplantation using multi-transgenic pigs. In press 2014.

41. Korbutt GS, Elliott JF, Ao Z, Smith DK, Warnock GL, Rajotte RV. Large scale isolation, growth, and function of porcine neonatal islet cells. J Clin Invest. 1996;97(9):2119-2129.

42. Emamaullee JA, Shapiro AM, Rajotte RV, Korbutt G, Elliott JF. Neonatal porcine islets exhibit natural resistance to hypoxia-induced apoptosis. Transplantation. 2006;82(7):945-952.
43. Graham ML, Bellin MD, Papas KK, Hering BJ, Schuurman HJ. Species incompatibilities in the pig-to-macaque islet xenotransplant model affect transplant outcome: a comparison with allotransplantation. Xenotransplantation. 2011;18(6):328-342.

44. Elliott RB. Towards xenotransplantation of pig islets in the clinic. Curr Opin Organ Transplant. 2011;16(2):195-200.

45. Heneine W, Tibell A, Switzer WM, et al. No evidence of infection with porcine endogenous retrovirus in recipients of porcine islet-cell xenografts. Lancet. 1998;352(9129):695-699.

46. Wynyard S, Nathu D, Garkavenko O, Denner J, Elliott R. Microbiological safety of the first clinical pig islet xenotransplantation trial in New Zealand. Xenotransplantation. Epub May 7, 2014.

47. Barton FB, Rickels MR, Alejandro R, et al. Improvement in outcomes of clinical islet transplantation: 1999-2010. Diabetes Care. 2012;35(7): 1436-1445.

48. Hering BJ, Cooper DKC, Cozzi E, et al. The International Xenotransplantation Association consensus statement on conditions for undertaking clinical trials of porcine islet products in type 1 diabetes executive summary. Xenotransplantation. 2009;16(4):196-202.

49. Onions D, Cooper DK, Alexander TJ, et al. An approach to the control of disease transmission in pig-to-human xenotransplantation. Xenotransplantation. 2000;7(2):143-155.

50. Patience C, Takeuchi Y, Weiss RA. Infection of human cells by an endogenous retrovirus of pigs. Nat Med. 1997;3(3):282-286.

51. Dieckhoff B, Petersen B, Kues WA, Kurth R, Niemann H, Denner J. Knockdown of porcine endogenous retrovirus (PERV) expression by PERV-specific shRNA in transgenic pigs. Xenotransplantation. 2008; 15(1):36-45.

52. Shapiro AM, Lakey JR, Ryan EA, et al. Islet transplantation in seven patients with type 1 diabetes mellitus using a glucocorticoid-free immunosuppressive regimen. $N$ Engl J Med. 2000;343(4):230-238.

53. Shapiro AM, Toso C, Imes S, et al. Five-year results of islet-alone transplantation match pancreas-alone transplantation with alemtuzumab, Tac/ MMF, with strong suppression of auto and alloreactivity [abstract]. Rev Diab Stud. 2011;8:95-96.

54. International Diabetes Federation. IDF Diabetes Atlas. 5th ed. Brussels: IDF; 2011.

55. Centers for Disease Control and Prevention. National Diabetes Fact Sheet, 2011. Atlanta: CDC; 2011. Available from: http://www.cdc.gov/ diabetes/pubs/pdf/ndfs_2011.pdf. Accessed July 10, 2014.
Transplant Research and Risk Management

\section{Publish your work in this journal}

Transplant Research and Risk Management is an international, peerreviewed open access journal focusing on all aspects of transplantation and risk management to achieve optimal outcomes in the recipient improving survival and quality of life. The journal welcomes submitted papers covering original research, basic science, clinical studies,
Dovepress

reviews \& evaluations, guidelines, expert opinion and commentary, case reports and extended reports. The manuscript management system is completely online and includes a very quick and fair peer-review system, which is all easy to use. Visit http://www.dovepress.com/ testimonials.php to read real quotes from published authors. 